\title{
The Role of Digital Technology in English Language Teaching in
} Azerbaijan

\author{
Milana Abbasova ${ }^{1} \&$ Narmin Mammadova ${ }^{1}$ \\ ${ }^{1}$ English Language and Literature Department, Khazar University, Baku, Azerbaijan \\ Correspondence: Milana Abbasova, English Language and Literature Department, Khazar University, Baku, \\ Mashati Ganjavi 41, Azerbaijan. E-mail: mabbasova@khazar.org
}

Received: January 9, 2019 Accepted: January 30, 2019 Online Published: March 2, 2019
doi:10.5539/ijel.v9n2p364
URL: https://doi.org/10.5539/ijel.v9n2p364

\begin{abstract}
The current study uses qualitative methodology to explore the role that digital technology plays in both second language acquisition and teaching. In-depth interviews were conducted with 6 teachers aged between 23 and 55 who are currently employed by Khazar University, Azerbaijan. Teachers indicate that the use of technology has an important impact on student's second language learning. Although some of the teachers displayed negative effects of modern technologies on getting students' attention, positive feedback is more available. Teachers demonstrated how the use of technology in teaching and learning supports students' engagement in education. Overall, this study provides a reader with a general understanding of both students and teachers' involvement in digital media as well as the effectiveness of second language teaching with technologies at higher educational institutions of Azerbaijan. Future research in the same area of study is needed to compare both teachers' and students' perceptions separately in broader sample and identify the key factors that affect teacher's decision to choose rather traditional methods.
\end{abstract}

Keywords: digital technologies, second language learning, modern education

\section{Introduction}

Over the last decade technology has become an inseparable part of teaching and learning environment. This technological evolution of humankind is an essential part of integration to the digital world with the help of teachers who can facilitate learners' learning process. In the current period, a number of institutions in Azerbaijan still have some sort of difficulties in catching up with the globalizing world. Not all the educational organizations are supplied with the appropriate teaching devices, such as overhead projectors, interactive whiteboards, laptop computers and other relevant facilities. The English language teachers face challenges in making ELT classes more effective and interesting by using digital technology. In many cases teachers are left to their own devices and the level of awareness of the usage of ICT among teachers is generally low. Majority of teachers in Azerbaijan use readily and easily available free online worksheets and tools. They find out the ways of using some findings through social networking or websites. Alongside with the above mentioned, students can develop their own pace of language learning and use supplemental teaching platforms which help them to revise and consolidate their knowledge by browsing the Internet at home.

Both teachers and students have an opportunity of being available in outdoor environment thanks to a myriad of internet browsers or applications. For instance, Skype helps to improve oral skills and creates new opportunities to develop students' communicative competences as the users have to pay active attention to what the interlocutor saying answer accordingly (Taillefer \& Munoz-Luna, 2014). It means that modern technology allows us real time communication as well. Correspondingly, both students and teachers should benefit from multimedia through different technology devices.

\subsection{Literature Review}

Digital technology is considered to be one of the most important drivers of linguistic change in a modern period. Over the last decade with its' remarkable entry as an educational device, the tradition of English Language teaching has drastically changed. Graddol claims:

"Technology lies at the heart of the globalization process; affecting education, work and culture. The use of English language has increased rapidly after 1960. At present the role and status of English is that it is the language of social context, political, sociocultural, business, education, industries, media, library, communication across 
borders, and key subject in curriculum and language of imparting education" (Gradol, 2000).

"Technology has turned into one essential aspect of society that helps students to understand the bigger picture of the world and not just stay confined to what schools and teachers teach them within their classrooms" (Warschauer, 2000).

Certainly, advanced technology has proved to be successful in replacing traditional methods. But it is really interesting whether contemporary teachers agree or disagree with the replacement of traditional teaching method with the modern one.

An overwhelming majority of teachers in Europe (90\%) use ICT to prepare their lessons (Chhabra, 2012). Outside the EU, the story seems to be the same. In the US, the institute of Educational Technology has developed a "National Educational Technology Plan" for transforming education through the power of technology (Motteram, 2013). It is evident that in most countries ICT is playing a crucial role in teaching and learning the English language. Even in the US an educational reform is being realized towards the implementation of technology in EFL classes.

Nowadays, many studies have been implemented to find out the answer to this key issue, and most of them have proved the importance of the usage of digital technology in EFL classes. For example, according to the results of the research conducted by teachers in Iran, they had positive attitudes regarding the use of technology in their classrooms. (Mollaei \& Riasati, 2013). Researchers from Saudi also reached the same conclusion that there is a positive correlation between a teacher's presence during a computer use and a Computer Assisted Language Learning (CALL) training and a positive attitude toward the use of Information and Communication Technologies (ICT), methodologies in learning. (Alshumaimeri, 2008). Moreover, Korean EFL teachers found out computer technology as a useful teaching tool that could easily support teaching methods by providing students with a variety of language inputs and increasing students' learning capabilities in real-life contexts (Park \& Son, 2009). According to Chong the advantages of using the Internet in the EFL classroom were listed as providing authentic materials for learners, making students meet native friends online, and assisting teacher-student communication (Chong, 2000). Teachers' individual interest in Internet use, teachers' skills at incorporating Internet resources in classroom tasks, and computer amenities and technical support in schools were the three key factors influencing the Internet use in the foreign language classroom (Shin \& Son, 2007).

In Azerbaijan and in most of the non-native speaking countries, English is used as a second or third language and for some people as a first language. With the spread and progress of English around the world, it has become an essential mean of communication among the people of different languages and cultures. At present, the role and status of English in Azerbaijan is higher than ever as it is a medium of instruction and curriculum in educational institutions. As the number of English learners is increasing, different teaching methods have been experimented to see the effectiveness of English language teaching. The use of technology in the form of films, radio, TV and tape recording has been repetition for a long time as well.

\section{Method}

This small-scaled research is going to represent the role of modern technologies in the Second Language Teaching at Khazar University from the perspective of teachers of the same institution. We are living in the era of digital technologies, nevertheless there is still insufficient supply and application of useful technologies within classroom settings. Primarily, loads of investigations have been done in this field of knowledge, although there is almost no empirical evidence on how technology influences the ways of language teaching within the framework of Azerbaijan universities.

\subsection{Research Questions}

By considering all these challenges, the questions below lead the whole study focusing on the analysis of the case through real experiences of the teachers of diverse backgrounds:

1) How does the use of digital technology by teachers support the teachers in second language teaching?

2) What are the advantages and disadvantages of applying modern technologies during teaching?

\subsection{Data Collection}

The study is driven by the qualitative paradigm of research as it endeavors to understand the phenomenon by dint of individual perceptions that are involved (Cohen \& Manion, 1994). As researchers, we have taken a deep interest in how teachers perceive the impacts of technological innovations on teaching strategies and to what extent they apply new tools as modern methods of teaching during "ESL" classes. Accordingly, interpretive approach has been applied to underpin this academic study by putting a huge reliance on the subjective 
experiences of participants (Reeves \& Hedberg, 2003). In respect with the interpretive paradigm, only interviewing as a meaning-oriented method of research is chosen to answer aforementioned research questions as it is considered to be the most relevant instrument in terms of "beliefs and meanings" (Arksey \& Knight, 1999). Interviews have been conducted to pursue the particular issues of concern in semi-structured model with a set of pre-planned core questions being mostly open-ended, as well as a limited amount of close-ended follow-up questions that were asked spontaneously to encourage the participants to interpret their opinions in details at some points (Shneiderman \& Plaisant, 2005). Only one semi-structured email interview has been taken from the oldest participant of the research by sending the questions in one single email as she was not able to participate in a face-to face interview due to her health problems. Rest of the in-depth interviews were held face-to-face within the university environment and recorded by means of cell phone's audio-recording program. The whole process was conducted in English Language.

\subsection{Participant Characteristics}

In respect with the research topic that focuses on second language teaching, the key participants of the small-scale study are teachers currently operating at Khazar University. Selected teachers were separated into three age groups being " $23-30$ ", "30-40" and " 40 and over" based on the assumption that older people might be more reluctant to make an effective use of digital divides in classroom settings (Pew Report, 2013).

\subsection{Sampling Procedures}

A purposeful method of sampling is applied to find the most productive sample with broader knowledge of area that took part voluntarily to answer the research questions mentioned above (Marshall, 2006). Sample size is quite small depending on the aim of the study, as it does not intend to build representative generalizations out of the conclusions.

\subsubsection{Sampling Size, Power and Precision}

Six teachers of academic staff at Khazar University gave their consent to take part in this study. Five of them were interviewed within the classroom settings at university and the other one chose to be interviewed via email. Although, the teachers are different depending on their age and years of experience, most of them are females (only one male) and four of them have an experience of studying abroad which can probably make them inclined to the use of technologies.

Table 1. Participants

\begin{tabular}{llllll}
\hline Teachers & Gender & Age & Place of Study & Experience & Taught Subject \\
\hline P1 & female & 24 & Azerbaijan/Korea & 1 year & ESL \\
P2 & female & 23 & Azerbaijan/UK & half-semester & ESL \\
P3 & female & 32 & Azerbaijan & 5 years & ESL; Translational Studies \\
P4 & male & 39 & Azerbaijan/UK & 15 years & ESL; ESP \\
P5 & female & 54 & Azerbaijan/USA & 31 years & ESL; ESP \\
P6 & female & 55 & Azerbaijan & 26 years & ESL; Translational Studies \\
\hline
\end{tabular}

\subsection{Data Analysis: Interviews}

In the first place, collected interview data through the audio recorder was transcribed and some direct notes taken during interviews added to the existing materials. Interview analysis has been done thoroughly by focusing on themes that describe meanings of self-evident subjects (Kvale, 1996).We took an hybrid approach of thematic scanning that connects a pre-set coding generated preliminarily from the theoretical framework to an open coding that emerged after carefully reading the written data (Gibbs, 2007). Themes that were identified both deductively prior to initial assay and inductively through the analysis of transcribed data are coded and categorized according to the interpretations of respondents in order to describe key points in similarity-based order (Maxwell \& Miller, 2008). Theme and codes arisen from first research question are indicated in hierarchical form as follows: 
Table 2. Interview analysis

\begin{tabular}{|c|c|c|}
\hline Themes & Codes & Sub-codes \\
\hline \multirow[t]{8}{*}{ Technologies used in Second Language Teaching } & Computer & - $\quad$ Videos \\
\hline & & - $\quad$ Pictures \\
\hline & & - $\quad$ Listening (Speakers) \\
\hline & & - $\quad$ Speaking \\
\hline & & - $\quad$ Mini Research \\
\hline & Mobile Phones & Online dictionary \\
\hline & Projector & PowerPoint presentations \\
\hline & Tablet & Showing quick information \\
\hline
\end{tabular}

\section{Results}

After getting the interview data analyzed, we were able to infer some key points among the teachers of different age groups towards the use of technologies within classroom settings.

\subsection{Digital Technologies as a Tool to Facilitate Teaching ESL}

The research questions were posed to find out the supportive side of technologies in terms of second language teaching. The interviews have revealed that there is a real reasoning between the second language teaching and the use of digital technologies. All the teachers emphasized its huge advantageous support to both teachers and students and called it as a demand of modern systems, however each of them owns individual attitude towards the use of them depending on variables such as their age group, experience and the subjects they teach.

\section{P1: 24 years old}

P1 does not conceive the classes without relevant digital amenities; otherwise, she thinks that it would be very boring for students. She mainly focuses on sound effects coming out of speakers and indispensable speed those devices provide us while searching for some information.

"We can use audio-recorder to record students' voice and then make them listen to their own pronunciation and correct it by showing the right one".

Computers and projectors are of common use in doing listening practices or showing presentations. "Smart Board" is an effective facility to teach any language, however she stresses its huge shortage in classrooms.

\section{P2: 23 years old}

P2 as a majority of interviewed teachers uses digital technologies in her classes based on what topic she plans to represent. While P1 focuses on sound and speed aspects of digital devices that make teaching process more effective, she believes in the strength of "visual teaching" and "visual memory". In this regard, video presentations are being applied to make students memorize unknown topics more easily:

"The main advantage is that it is good for applying knowledge you have learned into the practice".

To her mind, there is nothing lacking in current classrooms in terms of technologies.

\section{P3: 32 years old}

P3 employs digital gadgets in each class as the subject she teaches requires technological involvement. Similar to P1, her focal usage also stands for listening activities and sound practices done via computer and speakers which in turn is of great importance in "Oral Translation".

"When I was a student, there was a lack of modern technologies needed for practices, so that I was not able to practice oral translations. Now, students have more access to the internet, to other forms of technologies which means they can do more practices than prevoius generation did".

She appreciates online dictionaries as well indicating their ability to save students' time. The most lacking tool is booths with electronic devices needed for simultaneous interpreting practices.

\section{P4: 39 years old}

The only male participant of the study promotes two key purposes while using digital technologies within classes:

"First, they help me teach the lessons, secondly, the students are modern and they are interested in cutting edge technology. So, when I use modern technology, they are more interested and more involved in our lessons".

P4 places a significant reliance both on listening and presenting practices based upon "visual memory and 
understanding". Accessibility is one of the most advantegeous sides for him as he can be aware of the latest materials or teaching methodology via the Internet sources.

"I always explain my students that they should be very happy because whatever they watch and listen now, at the same time all people in the world, for example, in America, in France, in the UK students can find and use the same materials".

However, he pointed out the deficiency of high-speed internet and personal laptops for students to do a mini research project during the classes.

\section{P5: 54 years old}

One of the oldest members of our research demonstrated an unusual correlation compared to the other teachers. P5 does not use any digital gadget during the teaching process.

"I only rely on myself, on my voice, on my notes and on direct communication with the students. I feel quite comfortable doing so".

Notwithstanding, she is convinced that making use of technological tools provides teachers with authentic materials and linguistic context they may want students to be exposed to.

She also agrees that it is a "technology era" and teachers should build bridge to young students' interests as they are good at acquiring lingual aspects much better in this respect.

"We can also use them as a part of lectures, you know, in a form of Powerpoint Presentations. I don't use it, but it doesn't mean that we shouldn't do it, it probably should be done".

Even as a non-user of technologies she shows more positive attitude and like previous participants, underlines the lack of "Smart Boards" as well.

\section{P6: 55 years old}

In comparison with P5, P6 is inclined to make use of technologies as an effective tool for teaching. As she teaches translational studies, she frequently utilizes computers and projectors to have students do listening and speaking activities by means of videos and audio CDs. PowerPoint presentations are used to explain new topics with visual charts and brief verbal explanations.

"Young people nowadays are so keen on technologies, thus they enlarged interest in new methods of teaching by using technologies".

Although there are sufficient tools for teaching technologically, she complains that special software needed to be set for students in all classrooms in order to teach a newly launched subject called "Computer Assisted Tools" effectively.

\subsection{Digital Technologies as a tool to Prevent Teaching ESL}

At the same time, while discussing the negative effects of digital devices, all the teachers seem to indicate at least one drawback. Majority of participants stressed that despite their privilages on second language teaching and learning process, they can also distract students from the main topic. Since the technology became a fundamental temptation of youth, it might be misused during the classes. According to P1 and P6, sometimes students are highly engaged in their portable devices, so that they do not pay any attention to teacher's speech. Similarly, P4 in his turn told that when they are asked to do some research on given topics, they may go through other options and overuse it by not even focusing on main points.

Meanwhile, P3 sets a different approach mainly consisting of plagiarism issues:

"Internet can distract students from the main topic especially in writing classes where they need to make their creativity work, or in research for preparing some presentations".

Simultaneously, P5 touches the topic of generation gap while talking about the disadvantages. As many instructors of older generation experience difficulties with understanding of digital tools, she kindly thinks that these technologies need to be trained to make use of it. Another drawback can be considered the matter of involvement and she explains her idea in following way:

"All we know how people talk about these modern technologies, how it alienates people, how it keeps everybody together but apart. We don't want that in our classes. We want to see a group of people working together, who exhange their ideas, who participate, are engaged naturally. Otherwise, they get involved in their computers, laptops, or cellphones and lose interest in traditional methods". 


\section{Discussion}

It is evident from the results that language teaching and the use of digital technologies are interconnected and can be considered as an inseparable part of language learning process. All the participants of the current study stressed the importance of the digital facilities for supporting both teachers and students. Although, they called it as a requirement of the current educational system; each of them individually showed their attitude towards the use of technological devices depending on variables such as their age group, experience and the subjects they teach.

By analyzing the findings for the research question 1, the benefits of the digital technology in English language teaching are considered to be really determinative particularly by the younger generation teachers (P1 \& P2) who understand and boost the idea of technology in ESL classes rather than the older generation teachers (P5 \& P6), since teachers of the new generation have grown up with digital technology and it is woven into their lives.

While taking interviews the respondents stressed some digital devices and the importance of their usage in English Language classes (audio video recorder, video presentations, online dictionaries, speakers and boothes with electronic devices, high speed internet and personal laptops).

\subsection{Audio Video Recorder}

As one of the technological means audio recorder is said to be useful in improving language skills like listening and speaking. P1 claims that while listening to their own speech in English language, students are able to determine their own pronunciation and sentence structure errors. Alongside with the above-mentioned issue by P1, audio recorder is a useful tool to compare students' pronunciations. The results of the study conducted by Lord (2008), also suggested that both the attitude and pronunciation of students improved. He claims that students became more concerned about the accuracy of their pronunciation after the study implemented.

The study settled by Brown (2012), revealed that the students appreciated the extra opportunities of oral output outside the classroom and felt that their pronunciation improved. As well as in most of the countries all over the world, in Azerbaijan, people tend to regard those who speak English without a foreign accent to be fluent and proficient. Therefore, teachers of Khazar University try to correct students' pronunciation errors while speaking, and provide them with prompt feedback in class. Brown noted that the goal of English pronunciation has recently become to achieve pronunciation that is intelligible in international communication (Brown, 2012).

\subsection{Video Presentations}

According to the findings P2 uses video presentations almost for each new material taken during the classes. In this way she stresses the 'visual memory' as a key factor. No doubt, if used correctly video presentations can bring educational opportunities that will help to understand and obtain new material easily. At the same time students are able to observe native speakers in authentic settings, speaking and using different accents, registers and paralinguistic rules like posture and gesture.

This finding matches with the results of the two studies carried by Ortis (2012) and Wagener (2006) which showed the positive implications of using video technology in the language classroom. Both of them came to the conclusion that video materials significantly contributed to the development of all three observed aspects: listening, translating skills, and students' vocabulary stock.

\subsection{Online Dictionaries, Speakers and Boothes with Electronic Devices}

P3 cannot imagine English classes, especially "Oral translation" classes without digital gadgets. She underlines the maintenance of sound practices and listening activities for which computers, speakers and boothes with electronic devices are of great importance.

\subsection{High Speed Internet and Personal Laptops}

The internet is a powerful tool that provides the potential for purposeful and powerful use of on-line and writing classes (Warschauer, 2000). Teachers can not only access the Internet for finding resources for their classes but also supply their own materials, knowledge and idea for other teachers via the Internet (Warschauer et al., 2000). In addition, Shetzer and Warschauer (2000) put forward that teachers need to learn how to use Internet tools with support and encouragement from their teaching situations. In other words, teachers should gain knowledge and develop skills to use the Internet in order to get the benefit enough of it.

Overall, the teachers that took part in our study stess the advantages of the digital technology. They named electronic devices as follows: audio video recorder, video presentations, online dictionaries, speakers and boothes with electronic devices, high speed internet and personal laptops. 
Although P5 claims that she does not use electronic devices at all, while teaching English language, she still stresses positive impact on the learning process. On the other hand linguists of the modern period state its importance and being one of the requirements in teaching any foreign language. "At present, eduactional institutions look for teachers who have a good command of English and ability to use innovative technologies for teaching to satisfy the need of an e-society" (Pablo, 2017).

\subsection{Advantages}

According to the research question 2, all the interviewed teachers emphasized the huge advantages of modern technologies applied during the teaching process for both teachers and students. They believe that the use of technological facilities in ESL classes may provide a better learning atmosphere and performance. However, older and middle aged teachers emphasize that it can also minimize interactivity as the students are just looking on the screen. They mention that it should be used only as a supplementary instrument for the language teachers. Young and Bush (2004) suggest that teachers should avoid "the temptation to use technologies without understanding the pedagogical implications of using them".

The younger teachers who have taken part in our study cannot imagine language classes without relevant digital facilities. They find it interesting for students, as students can be engaged, during the whole lesson mainly with listening and speaking tasks conducted with the help of technological devices.

P2 mentions "visual memory", "visual teaching" as the main advantage. According to the findings, the other advantage is easy accessibility of the online dictionaries. P3 mentions that even a decade before as a university student she could not get the use of digital technology. She says that, current generation and the upcoming one are lucky because they are and will be able to practice language skills from various aspects using advanced technology. P4 even gives explanations of technological advantage to his students. He stresses that, in the modern time students are lucky because they can listen to native speakers even not going abroad and get information directly from the first hand.

P4 mentions that students are fully involved into the lesson and they really have temptation towards advanced technology. However, P5 and P6 reminds that their engagement can bring to the overuse and mislead the students during the teaching process. However we should not forget about the advantages which exceed the disadvantages. Min Pun (2004) gives some most important advantages of the use of digital technology:

1) Motivates students to learn English.

2) Develops students' communicative competence.

3) Widens students' knowledge about the culture of English.

4) Improves teaching efficiency.

5) Enhances interaction among students and between teachers and students.

6) Creates a conductive teaching environment in the classrooms.

7) Provides opportunities for English teaching outside the classrooms.

\subsection{Disadvantages}

Alike younger and middle-aged generation, older ones put forward some disadvantages of using advanced technology:

- It can distract from the main topic.

- Students may misuse it.

- It can bring to unconscious overuse by students.

- It puts a gap between teaching methods - the traditional and modern ones.

- It can take apart interactivity, exchange of ideas and natural engagement during the ESL classes.

According to Min Pun's (2004) study results there are many disadvantages of using digital technology in the context of non-native speaking countries:

1) Emphasis on the supplementary of effective teaching

2) Lack of communication between teachers and students

3) Lack of real-time teaching

4) Loss of students' logical thinking. 
5) Expensive way of conducting language classes.

\section{Recommendations}

Advanced technology and language teaching have gone hand to hand for a long time contributing to language classes as teaching facilities. However, many teachers all over the world have certain gaps and insecurity in benefiting from them. Deborah Healey says, "The pace and extent of technology for teaching, however, have made it difficult for many teachers, teacher educators, and administrators to know how best to employ computers, other forms of digital technology, and the global interaction enabled by the internet in language teaching" (Healey, 2011). If digital technology is utilized properly in ESL classes, without being overused, the language learners can be able to make full use in developing their overall language skills. In this case, the solutions for the teachers of older generation and for those teachers who are still not aware of the benefits of digital technology are as follows:

- Organizing panel meetings with teachers of older generation, and sharing ideas about the usage and benefits of digital technologies in ESL teaching and learning.

- Holding a demo lesson with the implication of advanced technology can also be demonstrated with the implication of advanced technology.

- Organizing a training session for teachers who are really not aware of digital technology.

Simultaneously, for broader understanding of the cases mentioned in this study, future researchers can choose a larger sample of teachers with mixed age and sex to scrutinize the real factors underlying their preference of traditional methods. Students can also be involved in further study of comparisons between the perceptions of students and teachers on the application of technologies in second language acquisition.

\section{References}

Alejandro Quezada, P. (2017). Schools in the context of E-education and e-society. 12th Iberian Conference on Information systems and technologies. Lisbon, Portugal.

Alshumaimeri, Y. A. (2008). Perceptions and attitudes toward using CALL in English classrooms among Saudi secondary EFL teachers. The JALT Call Journal, 44(2), 29-66.

Arksey, H., \& Knight, P. (1999) Interviewing for Social Scientists. London: Sage. https://doi.org/10.4135/9781849209335

Brown, B. (2012). Raising student awareness of pronunciation and exploring out-of-class approaches to pronunciation practice. Research Notes, 48, 18-23.

Chhabra, S. (2012). ICTs for advancing rural communities and human development. Information Science Reference, Hershey, PA.

Chong, D. (2000). The Practical Considerations of the Internet in the EFL Classroom. Multimedia-Assisted Language Learning, 3(2), 9-35.

Cohen, L., \& Manion, L. (1994). Research Methods in Education (4th ed.). London: Routledge.

Gibbs, G. (2007). Analyzing Qualitative Data. New York, USA: SAGE Publications Ltd. https://doi.org/10.4135/9781849208574

Graddol, D. (2000). The future of English? A guide to forecasting the popularity of the English language in the 21st century. London: The British Council.

Healey, D. (2011). TESOL technology standards. Alexandria, Va.: Teachers of English to Speakers of Other Languages.

Kvale, S. (1996). Interview Views: An Introduction to Qualitative Research Interviewing. Thousand Oaks, CA: Sage Publications.

Lord, G. (2008). Podcasting communities and second language pronunciation. Foreign Language Annals, 41(2), 364-379.

Marshall, M. N. (1996). Sampling for qualitative research. Family Practice, 13(6), 522-526.

Maxwell, J. A., \& Miller, B. A. (2008). Categorizing and connecting strategies in qualitative data analysis. Handbook of Emergent Methods, 461-477.

McNulty, A., \& Lazarevic, B. (2012). Best practices in using video technology to promote second language acquisition. Teaching English with Technology, 3, 49-61. 
Mollaei, F., \& Riasati, M. (2013). Teachers' Perceptions of Using Technology in Teaching EFL. International Journal of Applied Linguistics \& English Literature, 2(1), 13-22. https://doi.org/10.7575/ijalel.v.2n.1p.13

Motteram, G. (2013). Innovations in Learning Technologies for English Language Teaching. British Council.

Park, C., \& Son, J. (2009). Implementing Computer-Assisted Language Learning in the EFL Classroom: Teachers' Perceptions and Perspectives. https://doi.org/10.5172/ijpl.5.2.80

Pun, M. (2014). The use of multimedia technology in English language teaching: a global perspective. Crossing the Border: International Journal of Interdisciplinary Studies, 1(1), 29-38.

Reeves, T. C., \& Hedberg, J. G. (2003). Interactive learning systems evaluation. Englewood Cliffs, New Jersey: Educational Technology Publications.

Shin, H. J., \& Son, J. B. (2007). EFL teachers' perceptions and perspectives on internet assisted language teaching. Computer-Assisted Language Learning Electronic Journal (CALL-EJ), 8(2). Retrieved from $\mathrm{http}: / /$ callej.org/journal/8-2/h-js j-bs.html

Shneiderman, B., \& Plaisant, C. (2005). Designing the user interface. Boston: Addison Wesley.

Taillefer, L., \& Munoz-Luna, R. (2014). Developing Oral Skills through Skype: A Language Project Analysis. Procedia - Social and Behavioral Sciences, 141, 260-264. https://doi.org/10.1016/j.sbspro.2014.05.045

Warschauer, M. (2000). The Changing Global Economy and the Future of English Teaching. TESOL Quarterly, 34(3), 511. https://doi.org/10.2307/3587741

Warschauer, M., \& Kern, R. (2000). Network-based language teaching. Cambridge: Cambridge University Press.

Young, C., \& Bush, J. (2004). Teaching the English language arts with Technology: A critical Approach and Pedagogical Framework. Contemporary Issues in Technology and Teacher Education, 4(1), 1-22.

\section{Copyrights}

Copyright for this article is retained by the author(s), with first publication rights granted to the journal.

This is an open-access article distributed under the terms and conditions of the Creative Commons Attribution license (http://creativecommons.org/licenses/by/4.0/). 